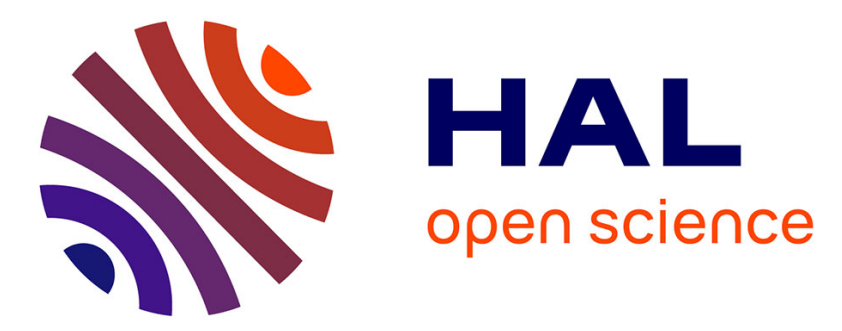

\title{
Association of postpartum depressive symptoms and urinary incontinence. A cohort study
}

\author{
Xavier Fritel, Tsegan Yawo Edem, Fabrice Pierre, Marie-Josèphe
}

Saurel-Cubizolles

\section{- To cite this version:}

Xavier Fritel, Tsegan Yawo Edem, Fabrice Pierre, Marie-Josèphe Saurel-Cubizolles. Association of postpartum depressive symptoms and urinary incontinence. A cohort study. European Journal of Obstetrics \& Gynecology and Reproductive Biology, 2016, 10.1016/j.ejogrb.2015.12.028 . inserm01262622

\section{HAL Id: inserm-01262622 https://www.hal.inserm.fr/inserm-01262622}

Submitted on 26 Jan 2016

HAL is a multi-disciplinary open access archive for the deposit and dissemination of scientific research documents, whether they are published or not. The documents may come from teaching and research institutions in France or abroad, or from public or private research centers.
L'archive ouverte pluridisciplinaire HAL, est destinée au dépôt et à la diffusion de documents scientifiques de niveau recherche, publiés ou non, émanant des établissements d'enseignement et de recherche français ou étrangers, des laboratoires publics ou privés. 
1 Title

2 Association of postpartum depressive symptoms and urinary incontinence. A cohort study.

3 Authors

4 Xavier Fritel ${ }^{1,2,3}$,

5 Yawo Edem Tsegan ${ }^{4}$,

6 Fabrice Pierre ${ }^{2}$,

7 Marie-Josèphe Saurel-Cubizolles ${ }^{4}$

8 and the "EDEN Mother-Child Cohort Study Group" (listed page 11)

9 Institutions

10 1. Université de Poitiers, Faculté de Médecine et Pharmacie, INSERM CIC1402, Poitiers, France.

11 2. CHU de Poitiers, Service de Gynécologie-Obstétrique et Médecine de la Reproduction, Poitiers,

12 France.

13 3. INSERM, CESP Centre for Research in Epidemiology and Population Health, U1018, Gender,

14 Sexual and Reproductive Health Team, Univ Paris-Sud, UMRS 1018, Kremlin-Bicêtre, France;

15 Institut National des Etudes Démographiques, Paris, France

16 4. INSERM UMR 1153, Obstetrical, Perinatal and Pediatric Epidemiology Research Team

17 (Epopé), Center for Epidemiology and Statistics Sorbonne-Paris-Cité, DHU Risks in pregnancy,

18 Paris Descartes University, France

19 Correspondence: Prof. Xavier Fritel, Service de Gynécologie et Obstétrique, CHU de Poitiers, 2

20 rue de la Milétrie, F-86000 Poitiers, France. Phone +33 549443 360; Fax +33 549443910.

$21 \quad$ xavier.fritel@univ-poitiers.fr

22 Word count: 224 for the abstract, and 2485 for the main text 


\section{Condensation:}

25 Clinician need to be aware that, although postpartum UI is often mild, it is followed by more new 26 cases of depression or antidepressant consumption.

27

28 
29 Association of depression and urinary incontinence. A cohort study

30 Fritel X, Tsegan YE, Pierre F, Saurel-Cubizolles MJ.

31 Abstract

32 Objective: Our objective was to clarify whether de novo urinary incontinence (UI) in the 33 postpartum period is associated with depressive symptoms or antidepressant drug consumption.

34 Study Design: 2002 pregnant women were recruited between 2003 and 2006 for the EDEN 35 mother-child cohort. This analysis included 1413 women who reported no UI before pregnancy.

36 Severity of UI was assessed by the Sandvik index. At 4 and 12 months postpartum, depressive 37 symptoms were assessed by the Edinburgh Postpartum Depression Scale (EPDS $\geq 10$ defines 38 depressive symptoms) and consumption of antidepressant drugs was reported.

39 Results: At 4 months postpartum, 198 women (14\%) reported de novo UI; 74\% (n=146) reported 40 mild UI, 26\% ( $\mathrm{n}=52)$ moderate, and none severe; prevalence of depressive symptoms was higher in 41 women with than without UI $(22.1 \%$ vs. $15.9 \%, \mathrm{p}=0.045)$, and consumption of antidepressant 42 drugs was more frequent $(4.7 \%$ vs. $1.4 \%, \mathrm{p}=0.005)$. At 12 months postpartum, the mean $( \pm \mathrm{SD})$

43 EPDS score differed between women with than without UI (7.30 \pm 3.46 vs. $6.57 \pm 3.72, \mathrm{p}=0.016)$

44 but was half that at 4 months postpartum. The incidence of new cases of depressive symptoms or 45 antidepressant consumption at 12 months was greater with than without UI (23.8\% vs. $15.3 \%$, $46 \mathrm{p}=0.012)$.

47 Conclusions: Although UI is mild in most cases at 4 months postpartum, it is followed by more 48 new cases of depressive symptoms or antidepressant consumption at 12 months.

49 Key words: postnatal depression, antidepressant consumption, postpartum care, urinary 50 incontinence, cohort study 


\section{Introduction}

53 Urinary incontinence (UI) is a common symptom after childbirth (1). Most often postnatal UI is

54 moderate and regresses after a few months (2). However, it can also persist and lead to deteriorated

55 quality of life and requests for care later in life $(3,4)$. Fear of postnatal UI can motivate women or

56 obstetricians to request elective caesarean section even without a medical indication (5).

57 The postnatal period is also a period susceptible to depressive symptoms, sometimes severe, that

58 could impair the relationship between the mother and her baby or even lead to suicide (6). In the

59 general population, women with UI may be more depressed than others (7). Postnatal UI appearing

60 de novo in women who were continent before pregnancy may induce or increase a depressive

61 syndrome. The few studies of the postnatal period show that postnatal UI is associated with

62 depressive symptoms $(8,9)$. However, these investigations did not determine a causal link between

63 the two situations.

64 A priori, risk factors of postnatal UI and those of postpartum depression differ. The main risk

65 factors for postnatal UI are obesity, maternal age, and vaginal childbirth. Muscle and neurological

66 vaginal birth trauma could explain the postnatal UI (10). The main risk factors for postnatal

67 depression are personal or family history of depression, stressful life events, low partner support, or

68 social isolation $(11,12)$.

69 We aimed to test whether de novo postpartum UI is related to altered mood or taking psychotropic

70 drugs and whether this association is maintained or increases over time. 


\section{Materials and methods}

73 The data were derived from the EDEN cohort (Etude sur les Déterminants pré et postnatals

74 précoces du développement psychomoteur et de la santé de l'ENfant,

75 https://eden.vjf.inserm.fr/index.php?lang=en), whose aim was to study the pre- and postnatal

76 determinants of child development and health. Study participation was proposed to all women

77 visiting the prenatal clinic before their 24th week of pregnancy in the university hospitals of Nancy

78 and Poitiers, our aim was to recruit women as early in pregnancy as possible. ${ }^{13}$ Exclusion criteria

79 were multiple pregnancies, known diabetes before pregnancy, French illiteracy or planning to move

80 out of the region within the next three years. Among the 3758 women invited to participate, 2002

81 (53\%) accepted to be enrolled in the study. Recruitment started in February 2003 and lasted 27

82 months in each centre (1034 women from Nancy and 968 from Poitiers). On average, women were

83 included at 15 weeks of pregnancy (range: 8-26). Their mean age was 29 years (range: 18-44) and

$8430 \%$ of the women were pregnant for the first time. Compared to the 2003 Enquête Nationale

85 Périnatale (National Perinatal Survey: a sample of births recruited throughout the country), ${ }^{14}$

86 women included in EDEN and still followed-up at delivery, had a higher level of education.

87 To be included in this secondary analysis, the women had to complete a questionnaire about UI

88 mailed 4 months after childbirth and declare that they did not have UI before the pregnancy. UI 4

89 months after birth was defined by a positive response to the question "during the past month have

90 you had involuntary leaking of urine?" The severity of incontinence was assessed by the Sandvik

91 severity index (15). This index is the product of the frequency and volume of leaks, ranging from 0

92 to 8. Four classes are defined for UI severity: 0, no incontinence; $1-2$, mild incontinence; 3-4,

93 moderate incontinence; 6-8, severe incontinence.

94 Depressive symptoms was assessed by questionnaires mailed 4 and 12 months postpartum by 2 95 indicators. The first, the Edinburgh Postpartum Depression Scale (EPDS), is a 10-item 96 questionnaire, responses to each item ranging from 0 to 3 (16). The overall score ranges from 0 to

9730 ; a score of 10 or higher defining probable depression. The second relates to the consumption of

98 antidepressant drugs in the month preceding the mailed questionnaire. 
99 Anthropometric and socio-demographic characteristics were maternal age at delivery grouped into 1004 classes: $<25$ years, 25-29, 30-34, $\geq 35$ years; educational level in 4 classes: below high school 101 diploma, high school diploma or equivalent, first university degree, above first university degree; 102 occupational group in 5 classes: 1) managers or professionals; 2) middle management; 3) office or 103 clerical workers and civil servants; 4) other employees in shops or services, farmers, and workers; 104 5) no paid occupation; marital status: married, part of an unmarried couple, or single; and body 105 mass index (BMI). Tobacco use in pregnancy and at 4 months postpartum was described in 106 dichotomic variables as smokers or non-smokers. For obstetric history, we retained the number of 107 deliveries and their mode (caesarean delivery only, at least one vaginal delivery); history of birth of 108 a baby weighing $\geq 4 \mathrm{~kg}$; and for the last delivery, mode of delivery (caesarean, vaginal 109 spontaneous, vaginal instrumental) and active second phase more than 30 min. Breastfeeding was 110 considered in 4 modalities: no breastfeeding, $\leq 10$ weeks, 11 to 17 weeks and still breastfeeding at 1114 months at completion of the questionnaire.

112 UI was described by its incidence. Risk factors were studied by bivariate analysis of the relation of 113 obstetric and socio-demographic data and UI (no, mild, moderate) by chi-square test. The relation 114 between de novo UI and postpartum depressive symptoms was studied by comparing the 115 proportion of depressed women and women consuming antidepressant drugs at 4 and 12 months.

116 We also studied new cases of depressive symptoms at 12 months after excluding cases reporting 117 depressive symptoms at 4 months. The mean change in EPDS score between months 4 and 12 118 postpartum was compared for women with and without de novo UI at 4 months; we also analysed 119 new cases of consumption of antidepressant drugs. Then to evaluate the relation between UI and 120 several risk factors simultaneously, multivariate analysis was performed by polytomic logistic 121 regression; only variables with $p<0.20$ on bivariate analysis were introduced in the multivariate 122 model, except for centre and mode of delivery which were forced in the multivariate model. A last 123 analysis restricted to women respondent to follow-up questionnaires (4 and 12 months) was 124 undergone to evaluate the relationship between UI and depressive symptoms or antidepressant 125 consumption, we used chi-square test for nominal variables and test for continuous variables; 
126 adjusted OR for age, occupational group, marital status, parity, and centre were estimated using a 127 logistic regression.

128 Data were analysed with SAS 9.3 (SAS Inst., Cary, NC). P $<0.05$ was considered statistically 129 significant.

130 The EDEN study received approval from the ethics committee (CCPPRB, Comite Consultatif de 131 Protection des Personnes en matière de Recherche Biomédicale) of Kremlin-Bicêtre Hospital on 132 December 12th, 2002. Informed written consent was obtained from mothers for herself at 133 enrolment and for her newborn child after delivery. The data files were registered with the French 134 Data Authority (CNIL, Commission Nationale Informatique et Libertés). 


\section{$136 \quad$ Results}

137 Among the 2002 women recruited during pregnancy, 1413 (71\%; mean age 29.5 years \pm 4.7 , range

138 17-44 years) were included in this analysis; 353 women who had not responded to questions about

139 UI and 236 who reported UI before pregnancy were excluded. Included women were older, with a

140 higher educational level, were more often in couple, and had a lower parity than excluded women

141 (Supplementary Table S1). In total, 14\% $(\mathrm{n}=198)$ declared de novo UI at 4 months postpartum;

$14274 \%(\mathrm{n}=146)$ were mild, $26 \%(\mathrm{n}=52)$ moderate, and none severe UI. The incontinence was related

143 to stress only (leakage during physical effort, coughing, or sneezing) for $37 \%(\mathrm{n}=74)$, urge only

144 (leakage related to an urgent need to urinate) for $9 \%(n=18)$, mixed (stress and urge) for $47 \%$

$145(\mathrm{n}=93)$ and other $7 \%(\mathrm{n}=13)$. Table 1 shows the frequency of the postpartum urinary incontinence

146 and its severity by medical and socio-demographic characteristics. Moreover, the frequency of UI

147 and its severity were not at all related to smoking during pregnancy neither at 4 months postpartum.

148 In the multivariate model of UI (no, mild, moderate), factors contributing to UI were the 149 occupational group, with the lowest risk among the more qualified occupations and a higher risk of 150 moderate incontinence among women without a paid job, as well as duration of the second active 151 phase of the last delivery, with a higher risk among women with a second phase of labour $\geq 30$ min 152 (Table 2).

153 At 4 months postpartum, 17.8\% (215/1210) of women reported depressive symptoms (EPDS $\geq 10$ )

154 or used antidepressants. The prevalence of depressive symptoms or antidepressant consumption 155 was higher for women with than without de novo postpartum UI (Table 3). With a more severe 156 definition of depression, the difference was still significant: the proportion of women with EPDS $\geq$ 15713 or using antidepressants was higher among women with UI than among women without UI $158(14.4 \%$ vs $8.7 \%, \mathrm{p}=0.02)$.

159 Among the 1413 women included in the analysis, 177 did not respond at 12 months postpartum; 160 12-month respondents were older, with a higher educational level, and were more often in couple 161 (Supplementary Table S2). At 1 year postpartum, the mean EPDS score remained higher for women with than without UI, but the difference was reduced by half between 4 and 12 months 
163 postpartum (1.41 vs 0.73 ; Table 3 ). At 1 year postpartum, they were no more significant difference

164 for depression or antidepressant consumption between women with and without de novo 165 postpartum UI when the analysis was adjusted for age, occupational group, marital status, parity,

166 and centre (Table 3). New cases of depressive symptoms or antidepressant consumption at 12 167 months were more frequent in women with than without UI at 4 months postpartum (Table 3). At 4 168 months postpartum, depressive symptoms or antidepressant consumption was more often reported 169 in case of urge UI $(50 \%, 7 / 14)$ than in case of mixed UI $(32 \%, 26 / 81)$ or stress UI $(15 \%, 10 / 67$; 170 analysis restricted to women respondent to both questionnaires, chi-square test, $\mathrm{p}=0.007)$. At 12 171 months postpartum we didn't find any difference related to UI type: depressive symptoms or 172 antidepressant consumption was reported by $7 \%$ in case of urge UI (1/14), $36 \%$ in case of mixed 173 UI (29/81), 24\% in case of stress UI (16/67); and 20\% (2/10) in case of other UI ( $\mathrm{p}=0.095)$. 


\section{Comment}

176 In our sample, UI at 4 months postpartum was often mild and was associated with an increased

177 postpartum depression screening score and frequent consumption of antidepressant drugs. Follow-

178 up at 1 year postpartum demonstrated that postnatal UI was associated with an increased number of

179 new cases of depressive symptoms or increased consumption of antidepressants. At 1 year

180 postpartum, the mean screening depression score differed between women with than without

181 postnatal UI, but the difference was reduced by half as compared with 4 months postpartum.

182 The strengths of our study are its longitudinal follow-up and the large number of women included.

183 We use a standardised measure of UI that incorporates assessment of symptom severity, and a

184 measurement of depressive symptoms at 2 time points in the first 12 months postpartum using a

185 well-validated measure. With successive questionnaires, the EDEN cohort allows an exploration of

186 the temporal relationship between UI and postnatal depression. One limitation is that urinary

187 symptoms and incontinence history were reported at four months postpartum and not before. This

188 may explain why only 236 women reported incontinence prior to pregnancy. Another limitation is

189 the secondary and exploratory nature of this analysis, which did not allow for calculating a number

190 of subjects required. The questionnaire for UI was not repeated at 12 months; therefore, the effect

191 of postnatal depression on incident UI was not explored. Likewise, we could not specify whether

192 the decrease observed between 4 and 12 months postpartum for the relation between UI and the

193 depression score is associated with decreasing UI prevalence. Another limitation is that depressed

194 women may over report UI condition. To examine this potential bias we performed an analysis

195 limited to women without depressive symptoms at the time of UI assessment (4 months

196 postpartum), and we observed more new case of depressive symptoms or antidepressant

197 consumption at 12 months in case of UI at 4 months.

198 Studies using the EPDS found a score $\geq 13$ in $7 \%$ to $17 \%$ of mothers between 6 weeks and 6 199 months after childbirth $(8,9,17)$. These results are similar to our findings $(8.2-10.5 \%)$. Results for 200 the mean EPDS score should be interpreted with caution because the mean score is not used in 
201 clinical practice. The scale was developed to detect postnatal depression by using a cut-off between

2029 and 13 depending on the sensitivity and specificity expected.

203 Postnatal UI prevalence is estimated between $6 \%$ and $21 \%$ and is often mild: in the cohort reported

204 by Altman et al., the prevalence of stress UI was $21 \%$ at 5 months postpartum and occurred less

205 than once a week for three quarters of women (18); for Viktrup et al., the UI prevalence was $6 \%$ at

2063 months postpartum and occurred daily for less than one quarter of women (1). In most cases,

207 women are not bothered by postnatal urinary symptoms (19).

208 In our longitudinal study, postnatal urinary incontinence reported at 4 months postpartum was

209 followed by an increase in new depression or intake of psychotropic drugs 8 months later. Brown

210 and Lumley interviewed 1336 women 6 to 7 months after giving birth: the risk of depression

211 (EPDS $\geq 13$ ) was multiplied by 2 with UI (8). Hullfish et al. interviewed 146 women 6 weeks after

212 childbirth: the depression score (EPDS) was associated with the urge incontinence quality of life

213 impact score (URGE-IIQ) but not urge incontinence symptoms (URGE-UDI) (9). In their

214 longitudinal study, van de Pol et al. found a relationship between overactive bladder syndrome and

215 depressive symptoms during pregnancy but not at 1 year postpartum (20). Mood disorders likely

216 increase the impact of incontinence on quality of life. Depression is known to decrease health-

217 related quality of life (21). Depression may be a factor favouring the reporting or complaining of

218 incontinence symptoms and happiness may favour ignoring or underreporting leakage. A cohort

219 study of older women (mean 60 years old) showed that depression was associated with incident UI,

220 but UI was not associated with incident depression (22).

221 Although postnatal UI in our sample was often mild, it was associated with increased incidence of

222 maternal depression or antidepressant use at 12 months postpartum. Thus, measuring the severity

223 of incontinence (leakage frequency and quantity) captures only a part of the problem experienced

224 by women. Clinicians need to be aware of the risk of depression associated with postnatal

225 incontinence. 


\section{Acknowledgements}

228 Members of the EDEN mother-child cohort study group are as follows: I. Annesi-Maesano, 229 JY. Bernard, J. Botton, M.A. Charles, P. Dargent-Molina, B. de Lauzon-Guillain, P. 230 Ducimetière, M. de Agostini, B. Foliguet, , A. Forhan, X. Fritel, A. Germa, V. Goua, R. 231 Hankard, B. Heude, M. Kaminski, B. Larroque†, N. Lelong, J. Lepeule, G. Magnin, L. 232 Marchand, C. Nabet, F. Pierre, R. Slama, M.J. Saurel-Cubizolles, M. Schweitzer, and O. 233 Thiebaugeorges.

\section{Funding}

236 We acknowledge all funding sources for the EDEN cohort: Fondation pour la Recherche 237 Médicale, Institut National de la Santé Et de la Recherche Médicale, Ministère de la 238 Recherche, Université Paris-Sud, Agence Nationale de la Recherche, Institut de Recherche 239 en Santé Publique, Agence Française pour la Surveillance et la Sécurité de l'Environnement 240 et du Travail, Institut National Pour l'Education et la Santé, Institut National de Veille 241 Sanitaire, Direction Générale de la Santé, Association de Langue Française pour l'Etude du 242 Diabète et du Métabolisme, Mutuelle Générale de l'Education Nationale, Nestlé, and the 243 European Commission (Seventh Framework Programme; Mechanisms of the Development 244 of Allergy). 


\section{References}

$1 \quad$ Viktrup L, Lose G, Rolff M, Barfoed K. The symptoms of stress incontinence caused by pregnancy or delivery in primiparas. Obstet Gynecol 1992;79:945-9.

2 Quiboeuf E, Saurel-Cubizolles M-J, Fritel X. Trends in urinary incontinence in women between 4 and 24 months postpartum in the EDEN cohort. BJOG 2015; DOI: 10.1111/1471-0528.13545

3 Saadoun K, Ringa V, Fritel X, Varnoux N, Zins M, Bréart G. Negative impact of urinary incontinence on quality of life, a cross-sectional study among women aged 49-61 years enrolled in the GAZEL cohort. Neurourol Urodyn 2006;25:696-702.

Fritel X, Ringa V, Varnoux N, Fauconnier A, Piault S, Bréart G. Mode of delivery and severe stress incontinence. A cross-sectional study among 2625 perimenopausal women. BJOG 2005;112:164651.

Al-Mufti R, McCarthy A, Fisk NM. Obstetricians' personal choice and mode of delivery. Lancet 1996;347:544.

Gissler M, Deneux-Tharaux C, Alexander S, et al. Pregnancy-related deaths in four regions of Europe and the United States in 1999-2000: Characterisation of unreported deaths. Eur J Obstet Gynecol Reprod Biol 2007;133:179-85.

Melville JL, Katon W, Delaney K, Newton K. Urinary incontinence in US women. Arch Intern Med $2005 ; 165: 537-42$.

Brown S, Lumley. Physical health problems after childbirth and maternal depression at six to seven months postpartum. BJOG 2000;107;1194-1201. urinary incontinence, and overactive bladder syndrome: is there an association? Int Urogynecol J 2007;18: 1121-6.

10 Baessler K, Schuessler B. Childbirth-induced trauma to the urethral continence mechanism: review and recommendations. Urology 2003;62:39-44.

11 Wisner KL, Parry BL, Piontek CM. Postpartum depression. New Engl J Med 2002;347:194-9. 
12 Woolhouse H1, Gartland D, Hegarty K, Donath S, Brown SJ. Depressive symptoms and intimate partner violence in the 12 months after childbirth: a prospective pregnancy cohort study. BJOG 2012;119:315-23.

13 Heude B, Forhan A, Slama R, et al. Cohort Profile: The EDEN mother-child cohort on the prenatal and early postnatal determinants of child health and development. Int J Epidemiol 2015. doi: 10.1093/ije/dyv151

14 Blondel B, Supernant K, Du Mazaubrun C, Bréart G. La santé périnatale en France métropolitaine de 1995 à 2003. Résultats des enquêtes nationales périnatales [Trends in perinatal health in metropolitan France between 1995 and 2003: results from the National Perinatal Surveys]. J Gynecol Obstet Biol Reprod 2006;35:373-87.

15 Sandvik H, Hunskaar S, Seim A, Hermstad R, Vanvik A, Bratt H. Validation of a severity index in female urinary incontinence and its implementation in an epidemiological survey. J Epidemiol Community Health 1993:47:497-9.

16 Cox JL, Holden JM, Sagovsky R. Detection of postnatal depression. Development of the 10-item Edinburgh Postnatal Depression Scale. Br J Psychiatry 1987;150:782-6.

17 McCandlish R, Bowler U, van Asten H, et al. A randomised controlled trial of care of the perineum during second stage of normal labour. BJOG 1998;105:1262-72.

18 Altman D, Ekström Á, Gustafsson C, Lopez A, Falconer C, Zetterström J. Risk of urinary incontinence after childbirth, a 10-year prospective cohort study. Obstet Gynecol 2006;108:873-8.

19 Van Brummen HJ, Bruinse HW, van de Pol G, Heintz APM, van der Vaart CH. Bothersome lower urinary tract symptoms 1 year after first delivery: prevalence and the effect of childbirth. BJU Int 2006;98:89-95.

20 van de Pol G, van Brummen HJ, Bruinse HW, Heintz AP, van der Vaart CH. Is there an association between depressive and urinary symptoms during and after pregnancy? Int Urogynecol J 2007;18:1409-15. 
21 ten Doesschate MC, Koeter MW, Bockting CL, Schene AH. Health related quality of life in recurrent depression: a comparison with a general population sample. J Affect Disord 2010;120:12632.

22 Melville L, Fan MY, Rau H, Nygaard IE, Katon WJ. Major depression and urinary incontinence in women: temporal associations in an epidemiologic sample. Am J Obstet Gynecol 2009;201:490.e17. 
Table 1. De novo urinary incontinence at 4 months postpartum and severity by women's characteristics. Chi' test.

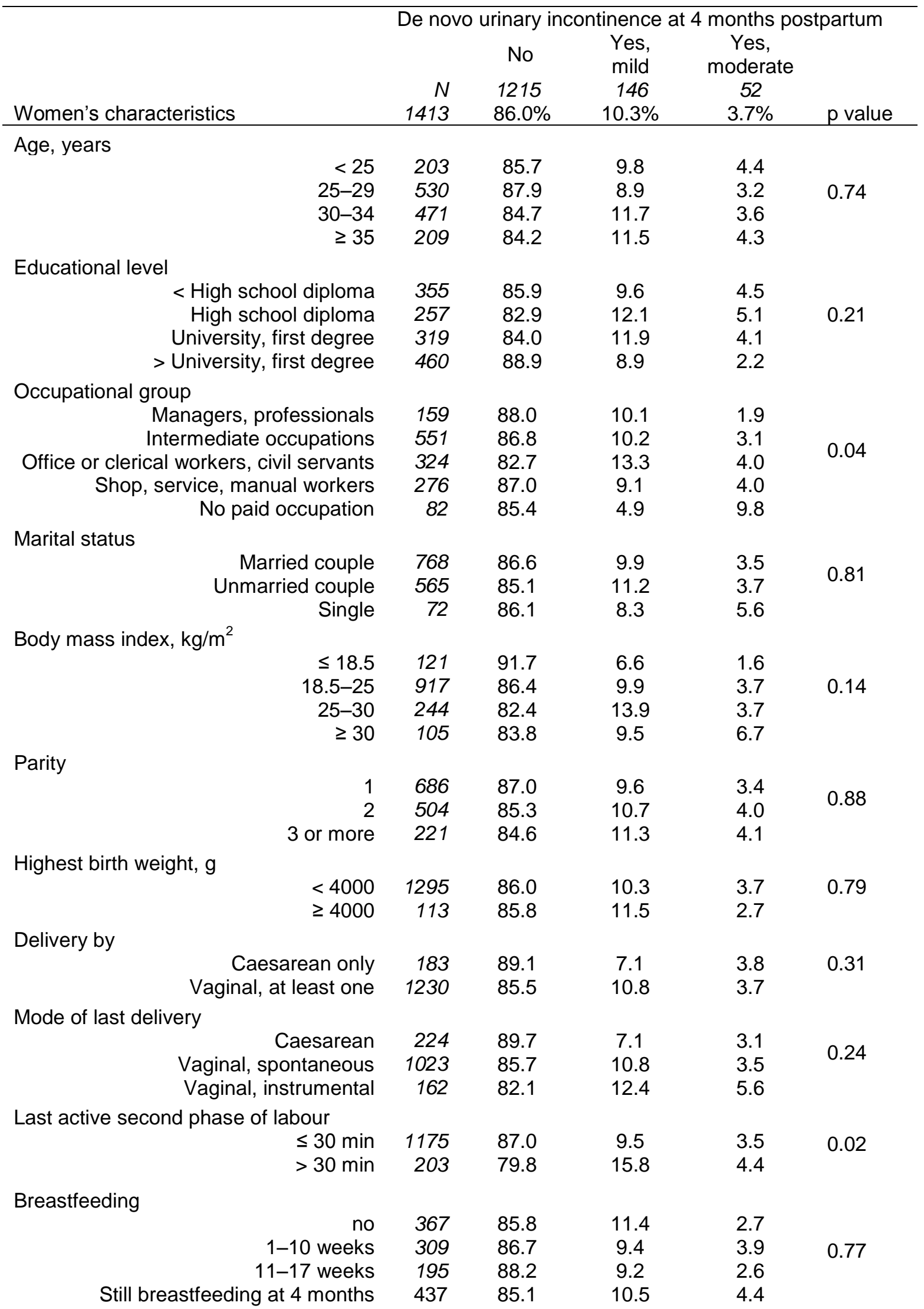




\begin{tabular}{|c|c|c|c|c|c|c|}
\hline \multirow[b]{4}{*}{ Women's characteristics } & & \multicolumn{5}{|c|}{ De novo urinary incontinence at 4 months postpartum } \\
\hline & & & No & Yes, & Yes, & \multirow[b]{3}{*}{ p value } \\
\hline & & $N$ & 1215 & 146 & 52 & \\
\hline & & 1413 & $86.0 \%$ & $10.3 \%$ & $3.7 \%$ & \\
\hline \multicolumn{7}{|l|}{ Smoking during pregnancy } \\
\hline & yes & 320 & 87.5 & 9.7 & 2.8 & 0.55 \\
\hline & no & 1060 & 85.7 & 10.3 & 4.1 & \\
\hline \multicolumn{7}{|c|}{ Smoking at 4 months postpartum } \\
\hline & yes & 313 & 87.2 & 9.6 & 3.2 & 0.75 \\
\hline & no & 1098 & 85.6 & 10.6 & 3.8 & \\
\hline
\end{tabular}


Table 2. Risk factors of de novo urinary incontinence (UI) at 4 months postpartum.

Polytomic logistic regression adjusted for centre.

De novo urinary incontinence at 4 months postpartum

Women's characteristics

No UI

Yes, mild

Yes, moderate

Adj OR $(95 \% \mathrm{Cl}) \quad$ Adj OR $(95 \% \mathrm{Cl})$

$p$ value

Occupational group

Managers, professionals Intermediate occupations

Office or clerical workers, civil servants

Shop, service, manual workers

No paid job

1
$1.02(0.6-1.8)$
$1.29(0.7-2.4)$
$0.86(0.4-1.7)$
$0.47(0.1-1.5)$

$0.62(0.3-1.4)$
1
$1.55(1.0-2.4)$
$1.08(0.5-2.2)$

$\leq 30 \min$
$>30 \min$

$\begin{array}{rr}\leq 18.5 & 1 \\ 18.5-25 & 1 \\ 25-30 & 1 \\ \geq 30 & 1\end{array}$

Last active second phase of labour

$$
>30 \mathrm{~min}
$$

Mode of last delivery

Caesarean
Vaginal, spontaneous
Vaginal, instrumental

1

$\begin{array}{cc}1 & 1 \\ 1 & 1.77(1.1-2.9)\end{array}$

$$
1.03(0.4-2.3)
$$

0.06

1
1
1
$1.51(0.8-2.7)$
$1.42(0.7-3.1)$ 
Table 3. De novo urinary incontinence 4 months postpartum and depressive symptoms at 4 and 12 months postpartum. Non-adjusted $p$ values, and adjusted odds ratios for age, occupational group, marital status, parity, and centre. Analysis restricted to women who responded both questionnaires ( 4 and 12 months postpartum; $\mathrm{N}=1226$ )

\begin{tabular}{|c|c|c|c|c|}
\hline Depression indicators & $\begin{array}{c}\text { De novo urinary } \\
\text { No } \\
\%(n / M) \text {, or } \\
\text { mean }( \pm \text { sd })\end{array}$ & $\begin{array}{c}\text { tinence at } 4 \text { mo } \\
\text { Yes } \\
\%(n / N) \text {, or } \\
\text { mean }( \pm s d)\end{array}$ & $\begin{array}{l}\text { postpartum } \\
\text { Non adjusted } \\
\text { p value }\end{array}$ & $\begin{array}{l}\text { Adjusted OR } \\
(95 \% \mathrm{Cl})\end{array}$ \\
\hline \multicolumn{5}{|l|}{4 months postpartum } \\
\hline Depressive symptoms (EPDS $\geq 10$ ) & $15.9(168 / 1054)$ & $22.1(38 / 172)$ & 0.045 & $1.47(0.98-2.21)$ \\
\hline Mean EPDS & $4.84(4.72)$ & $6.25(4.84)$ & 0.001 & \\
\hline Antidepressant consumption & $1.4(15 / 1040)$ & $4.7(8 / 170)$ & 0.005 & $3.13(1.23-7.92)$ \\
\hline $\begin{array}{l}\text { Depressive symptoms (EPDS } \geq 10 \text { ) } \\
\text { or antidepressant consumption }\end{array}$ & $16.5(172 / 1040)$ & $25.3(43 / 170)$ & 0.006 & $1.67(1.13-2.47)$ \\
\hline \multicolumn{5}{|l|}{12 months postpartum } \\
\hline Depressive symptoms (EPDS $\geq 10$ ) & $20.5(216 / 1054)$ & $24.4(42 / 172)$ & 0.242 & $1.18(0.80-1.75)$ \\
\hline Mean EPDS & $6.57(3.72)$ & $7.30(3.46)$ & 0.016 & \\
\hline $\begin{array}{l}\text { Mean EPDS change between } \\
4 \text { and } 12 \text { months postpartum }\end{array}$ & $+1.72(4.45)$ & $+1.05(4.45)$ & 0.067 & \\
\hline Antidepressant consumption & $2.8(29 / 1048)$ & $4.2(7 / 166)$ & 0.306 & $1.43(0.61-3.37)$ \\
\hline $\begin{array}{l}\text { Depressive symptoms (EPDS } \geq 10 \text { ) } \\
\text { or antidepressant consumption }\end{array}$ & $22.0(228 / 1036)$ & $28.9(48 / 166)$ & 0.049 & $1.37(0.94-1.99)$ \\
\hline \multicolumn{5}{|c|}{ New cases of depressive symptoms or antidepressant consumption at 12 months postpartum $\ddagger$} \\
\hline Depressive symptoms (EPDS $\geq 10$ ) & $14.4(128 / 886)$ & $20.9(28 / 134)$ & 0.053 & $1.53(0.96-2.43)$ \\
\hline Antidepressant consumption & $1.5(13 / 865)$ & $1.6(2 / 126)$ & 0.928 & $0.85(0.24-2.92)$ \\
\hline $\begin{array}{l}\text { Depressive symptoms (EPDS } \geq 10 \text { ) } \\
\text { or antidepressant consumption }\end{array}$ & $15.3(132 / 865)$ & $23.8(30 / 126)$ & 0.012 & $1.70(1.08-2.70)$ \\
\hline
\end{tabular}

¥ New cases of depressive symptoms or antidepressant consumption among women not reporting depressive symptoms or taking antidepressant at 4 months postpartum 
Table S1. Characteristics of excluded women from the analysis (Chi ${ }^{2}$ test).

\begin{tabular}{|c|c|c|c|}
\hline & $\begin{array}{c}\text { Included women } \\
\qquad \begin{array}{c}\mathrm{N}=1413 \\
\%\end{array}\end{array}$ & $\begin{array}{l}\text { Excluded women } \\
\qquad \begin{array}{c}\mathrm{N}=589 \\
\%\end{array}\end{array}$ & $\mathrm{p}$ \\
\hline \multicolumn{4}{|l|}{ Age, years } \\
\hline less than 25 & 14.4 & 20.1 & \multirow{4}{*}{$<0.001$} \\
\hline $25-29$ & 37.5 & 28.5 & \\
\hline $30-34$ & 33.3 & 32.8 & \\
\hline 35 or more & 14.8 & 18.7 & \\
\hline \multicolumn{4}{|l|}{ Educational level } \\
\hline$<$ High school diploma & 25.5 & 38.5 & \multirow{4}{*}{$<0.001$} \\
\hline High school diploma & 18.5 & 16.6 & \\
\hline University, $1^{\text {st }}$ degree & 22.9 & 18.2 & \\
\hline$>$ University, $1^{\text {st }}$ degree & 33.1 & 26.7 & \\
\hline \multicolumn{4}{|l|}{ Occupational group } \\
\hline Managers, professionals & 11.4 & 9.9 & \multirow{5}{*}{$<0.001$} \\
\hline Intermediate occupation & 39.6 & 31.6 & \\
\hline Office or clerical workers, civil servants & 23.3 & 18.6 & \\
\hline Shop, service, manual workers & 19.8 & 32.7 & \\
\hline No paid occupation & 5.9 & 7.1 & \\
\hline \multicolumn{4}{|l|}{ Marital status } \\
\hline Married couple & 54.7 & 46.1 & \multirow{3}{*}{$<0.001$} \\
\hline Unmarried couple & 40.2 & 44.0 & \\
\hline Single & 5.1 & 9.9 & \\
\hline \multicolumn{4}{|l|}{ Parity } \\
\hline 0 & 48.6 & 32.9 & \multirow{4}{*}{$<0.001$} \\
\hline 1 & 35.7 & 39.4 & \\
\hline 2 & 11.7 & 18.9 & \\
\hline 3 or more & 4.0 & 8.7 & \\
\hline
\end{tabular}


Table S2. Characteristics of women who did not fill the 12 months questionnaire among those included in the analysis (Chi ${ }^{2}$ test).

\begin{tabular}{|c|c|c|c|}
\hline & $\begin{array}{c}\text { Women without a } \\
\text { follow-up at } 12 \\
\text { months postpartum } \\
\mathrm{N}=177 \\
\%\end{array}$ & $\begin{array}{c}\text { Women with a } \\
\text { follow-up at } 12 \\
\text { months postpartum } \\
N=1236 \\
\%\end{array}$ & $\mathrm{p}$ \\
\hline Age, years & $\mathrm{N}=177$ & $\mathrm{~N}=1236$ & \multirow{5}{*}{0.0002} \\
\hline less than 25 & 24.3 & 12.9 & \\
\hline $25-29$ & 39.0 & 37.3 & \\
\hline $30-34$ & 26.6 & 34.3 & \\
\hline 35 or more & 10.2 & 15.4 & \\
\hline Educational level & $\mathrm{N}=175$ & $\mathrm{~N}=1216$ & \multirow{5}{*}{$<0.0001$} \\
\hline$<$ High school diploma & 41.1 & 23.3 & \\
\hline High school diploma & 17.7 & 18.6 & \\
\hline University, $1^{\text {st }}$ degree & 20.6 & 23.3 & \\
\hline > University, $1^{\text {st }}$ degree & 20.6 & 34.9 & \\
\hline Occupational group & $N=176$ & $\mathrm{~N}=1216$ & \multirow{5}{*}{0.0005} \\
\hline Managers, professionals & 6.2 & 12.2 & \\
\hline Intermediate occupations & 31.2 & 40.8 & \\
\hline Office or clerical workers, civil servants & 25.0 & 23.0 & \\
\hline Shop, service, manual workers & 30.1 & 18.3 & \\
\hline Marital status & $N=175$ & $\mathrm{~N}=1230$ & \multirow{4}{*}{0.0006} \\
\hline Married couple & 47.4 & 55.7 & \\
\hline Unmarried couple & 41.7 & 40.0 & \\
\hline Single & 10.9 & 4.3 & \\
\hline Parity & $N=177$ & $N=1236$ & \multirow{5}{*}{0.389} \\
\hline 0 & 46.9 & 48.9 & \\
\hline 1 & 35.0 & 35.8 & \\
\hline 2 & 15.2 & 11.2 & \\
\hline 3 or more & 2.8 & 4.1 & \\
\hline
\end{tabular}

